\title{
ORIGINAL ARTICLE Selective loss of parvalbumin-positive GABAergic interneurons in the cerebral cortex of maternally stressed Gadl-heterozygous mouse offspring
}

\author{
T Uchida ${ }^{1,3}$, T Furukawa ${ }^{1}$, S Iwata ${ }^{1}$, Y Yanagawa ${ }^{2}$ and A Fukuda ${ }^{1}$
}

Exposure to maternal stress (MS) and mutations in GAD1, which encodes the $\gamma$-aminobutyric acid (GABA) synthesizing enzyme glutamate decarboxylase (GAD) 67, are both risk factors for psychiatric disorders. However, the relationship between these risk factors remains unclear. Interestingly, the critical period of MS for psychiatric disorders in offspring corresponds to the period of GABAergic neuron neurogenesis and migration in the fetal brain, that is, in the late stage of gestation. Indeed, decrement of parvalbumin (PV)-positive GABAergic interneurons in the medial prefrontal cortex (mPFC) and hippocampus (HIP) has often been observed in schizophrenia patients. In the present study, we used GAD67-green fluorescent protein (GFP) knock-in mice (that is, mice in which the Gad1 gene is heterozygously deleted; GAD67 ${ }^{+/ G F P}$ ) that underwent prenatal stress from embryonic day 15.0 to 17.5 and monitored PV-positive GABAergic neurons to address the interaction between Gad1 disruption and stress. Administration of 5-bromo-2-deoxyuridine revealed that neurogenesis of GFP-positive GABAergic neurons, but not cortical plate cells, was significantly diminished in fetal brains during MS. Differential expression of glucocorticoid receptors by different progenitor cell types may underlie this differential outcome. Postnatally, the density of PV-positive, but not PV-negative, GABAergic neurons was significantly decreased in the MPFC, HIP and somatosensory cortex but not in the motor cortex of GAD67 ${ }^{+/ G F P}$ mice. By contrast, these findings were not observed in wild-type $\left({\left.\mathrm{GAD} 67^{+/+}\right)}\right.$offspring. These results suggest that prenatal stress, in addition to heterozygous deletion of Gad1, could specifically disturb the proliferation of neurons destined to be PV-positive GABAergic interneurons.

Translational Psychiatry (2014) 4, e371; doi:10.1038/tp.2014.13; published online 11 March 2014

Keywords: GAD67; glucocorticoid receptor; neurogenesis; parvalbumin; prenatal stress; schizophrenia

\section{INTRODUCTION}

Environmental factors, such as maternal stress (MS), have been linked to psychiatric disorders in offspring, including schizophrenia. ${ }^{1,2}$ In addition, psychological stress in pregnant women is associated with childhood adjustment disorders in their offspring. ${ }^{3}$ In support of temporal specificity for the effects of stress on long-term brain developmental disorders, an epidemiological study reported a significant association between MS experienced during pregnancy and an increased risk of schizophrenia in offspring. ${ }^{4}$ Comparable behavioral disruptions are observed in animals that have experienced prenatal stress. ${ }^{5,6}$

During sensitive periods of development, adverse events such as stress can readily trigger epigenetic alterations, which can adversely affect physiological function and behavior in adulthood. ${ }^{7,8}$ The fetal period involves dynamic development of the cerebral cortex and the hippocampus (HIP), and excess stress hormone levels can cause cell loss in these sensitive brain areas. ${ }^{9}$ Interestingly, the period of highest vulnerability to prenatal stress has been matched to the peak period of proliferation and migration of neurons during hippocampal and cortical development. $^{10}$
Whereas differentiated excitatory glutamatergic pyramidal neurons originate from the ventricular zone (VZ) of the dorsal telencephalon form the cortical plate (CP), ${ }^{11}$ GABAergic neurons are born in the VZ of the ventral telencephalon in the medial ganglionic eminence (MGE). ${ }^{12-14}$ Postmitotic MGE-derived neurons exit proliferative domains through intricate but highly stereotyped pathways, migrating dorsally toward the neocortex and caudally to the HIP. ${ }^{15}$

Strong evidence indicates that the GABA-related system is impaired in schizophrenia. ${ }^{16-19}$ In particular, studies have indicated reductions in cortical GABA content ${ }^{20}$ and the activity of glutamate decarboxylase (GAD) $67,,^{21-23}$ a GABA synthesizing enzyme. In childhood-onset schizophrenia cases, Addington et al. ${ }^{24}$ observed significant overtransmission of alleles at several adjacent SNPs in the $5^{\prime}$ region of the GAD1 gene encoding GAD67, suggesting that GAD1 may be a fairly common genetic risk factor for schizophrenia. GABAergic interneurons are classified by diverse molecular, morphological and physiological properties. ${ }^{25}$ Notably, GABA-related abnormalities in schizophrenia and related disorders are largely exclusive to the basket and chandelier types of neurons expressing parvalbumin (PV). ${ }^{26-28}$

\footnotetext{
${ }^{1}$ Department of Neurophysiology, Hamamatsu University School of Medicine, Hamamatsu, Japan and ${ }^{2}$ Department of Genetic and Behavioral Neuroscience, Gunma University Graduate School of Medicine, Maebashi, Japan. Correspondence: Professor A Fukuda, Department of Neurophysiology, Hamamatsu University School of Medicine, 20-1 Handayama 1-chome, Higashi-ku, Hamamatsu, Shizuoka 431-3192, Japan.

E-mail: axfukuda@hama-med.ac.jp

${ }^{3}$ Current address: Central Research Institute for the Pathomechanisms of Epilepsy, Fukuoka University, Fukuoka, Japan.

Received 6 November 2013; revised 5 January 2014; accepted 30 January 2014
} 
Although the pathogenesis and pathophysiology of schizophrenia and other psychiatric disorders involve multiple factors, such as MS (or prenatal stress), impairment of GAD67 and loss of PV-positive GABA neurons, the relationship among these factors is unknown. We previously established an MS model using GAD67green fluorescent protein (GFP) knock-in mice. ${ }^{29}$ In GAD67-GFP knock-in mice, GFP was specifically expressed in GABAergic neurons under the control of the endogenous Gad1 promoter, and these knock-in mice have helped to elucidate the development of GABAergic neurons. ${ }^{30,31}$ In addition, the protein expression level of GAD67 was shown to be reduced in heterozygous GAD67-GFP knock-in (GAD67 ${ }^{+/ G F P}$ ) mice because of disruption of the endogenous Gad1 gene. ${ }^{32}$ Therefore, in addition to its consistent labeling of GABAergic neurons, the GAD67 $7^{+/ G F P}$ mouse is useful for the study of decreased GAD67 levels with Gad1 gene disruption. Because this model shows higher vulnerability to MS in

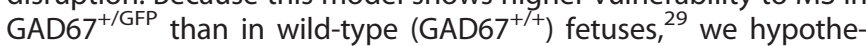
sized that MS with GAD1 abnormalities may affect neurogenesis and/or migration of PV-positive GABAergic neurons. Using this model, we investigated the gene-environment interaction between MS and fetal Gad1 deletion as an interactive risk factor for psychiatric disorders, including schizophrenia. Our results confirm that GAD67 ${ }^{+/ G F P}$ mice exposed to MS show an anatomical phenotype of PV-positive GABAergic neurons similar to that observed in psychiatric and autistic patients.

\section{MATERIALS AND METHODS}

\section{Animals}

All procedures were conducted in accordance with the guiding principles of the $\mathrm{NIH}$, under the review and approval of the Guide for the Care and Use of Laboratory Animals of Hamamatsu University School of Medicine, Japan. Every effort was made to minimize the number and suffering of the animals used. The generation of GAD67-GFP ( $\Delta$ neo) mice has been described previously. ${ }^{30}$ In brief, as a consequence of replacement of the endogenous Gad1 gene by the gfp gene, GAD67 protein and ambient GABA levels in the GAD67 $7^{+/ G F P}$ brain are reduced by $\sim 50 \%$ relative to the wild-type $\left({\mathrm{GAD} 67^{+/+}}^{+}\right.$) brain. ${ }^{32,33}$ In the present study, female GAD67 $7^{+/+}$ mice (Japan SLC, Hamamatsu, Japan) were placed overnight with male ( $>9$ weeks) GAD67 $7^{+/ G F P}$ mice in a cage under a 12-h light-dark cycle (lights off from 1800 to 0700 hours). The day when a plug was identified was defined as embryonic day (E) 0 . For postnatal experiments, mothers were changed to naive surrogate mothers with the same delivery date at postnatal day $(P) 0$. Pups were bred until P21 with their surrogate mother.

\section{Maternal restraint-and-light stress}

The procedure of maternal restraint-and-light stress was described previously. ${ }^{29}$ In brief, the stress procedure was performed three times a day for $45 \mathrm{~min}$ per session (0830-0915 hours, 0030-1315 hours and 1630-1715 hours) from E15.0 to E17.5 with a transparent plastic tube with a diameter of $3 \mathrm{~cm}$.

\section{BrdU administration}

Pregnant mice were intraperitoneally injected with 5-bromo-2deoxyuridine (BrdU, $50 \mathrm{mg} \mathrm{kg}^{-1}$; Sigma-Aldrich, Tokyo, Japan) dissolved in $0.1 \mathrm{M}$ phosphate-buffered saline (PBS) once at E15.0 or E12.0.

\section{Immunohistochemistry}

Pregnant mothers were deeply anesthetized with pentobarbital sodium ( $50 \mathrm{mg} \mathrm{kg}^{-1}$, intraperitoneally), and fetuses were dissected out after the final stress session. GAD67 $7^{+/ G F P}$ fetuses were perfused intracardially with fixative solution consisting of $4 \%(\mathrm{w} / \mathrm{v})$ paraformaldehyde in $0.1 \mathrm{M}$ PBS Coronal sections ( $25 \mu \mathrm{m}$-thick) were treated with $2 \mathrm{~N} \mathrm{HCl}$ for $1 \mathrm{~h}$ at $37^{\circ} \mathrm{C}$ blocked with $10 \%(\mathrm{v} / \mathrm{v})$ horse serum in PBS and $0.5 \%(\mathrm{v} / \mathrm{v})$ Triton X-100 (PBST) and incubated with primary antibodies against GFP (A11122, Life Technologies, Tokyo, Japan, rabbit polyclonal 1:1000) and BrdU (B44, Becton Dickinson, Franklin Lakes, NJ, USA, mouse monoclonal, 1:400 overnight at $4{ }^{\circ} \mathrm{C}$. Sections were then incubated with secondary antibodies
(AlexaFluor 488 anti-rabbit, AlexaFluor 546 anti-mouse, Life Technologies, Eugene, OR, USA) for $2 \mathrm{~h}$ at room temperature.

For determination of glucocorticoid receptor (GR) distribution and cell proliferation, sections from $\mathrm{GAD}^{+/+}$fetuses were treated with $100 \%(\mathrm{v} / \mathrm{v})$ methanol for $10 \mathrm{~min}$ and then incubated with an anti-GR antibody (ab9568, Abcam, Tokyo, Japan, mouse monoclonal 1:200) and anti-Ki-67 antibody (CRM325, Biocare Medical, Concord, CA, USA, rabbit monoclonal $1: 100)$ overnight at $4^{\circ} \mathrm{C}$. After washing, sections were incubated with secondary antibodies for $2 \mathrm{~h}$ at room temperature.

P21 male GAD67 $7^{+/ G F P}$ and GAD67/++ mice were anesthetized and intracardially perfused with fixative solution. Brain sections were prepared as above, and GFP and BrdU double immunostaining was performed. For double immunostaining of GFP and PV, sections were first immunostained for GFP. For double immunostaining of GAD67 and PV in P21 GAD67 $7^{+/+}$ mice, anti-GAD67 (MAB5406, Millipore-Japan, Tokyo, Japan, mouse monoclonal, 1:2000) and AlexaFluor 488 anti-mouse antibodies were applied first, followed by incubation with the anti-PV antibody $(\mathrm{PC} 255 \mathrm{~L}$, Calbiochem, San Diego, CA, USA, rabbit polyclonal, 1:200) overnight at $4{ }^{\circ} \mathrm{C}$ and the secondary antibody for $2 \mathrm{~h}$ at room temperature.

\section{Cell counting}

We attempted to ensure unbiased counting ${ }^{34,35}$ as follows. In brief, to prevent overcounting, we configured a single rectangular region of interest within each brain region to prevent double counting of cells. The section thickness was consistent, and multiple sections were counted from the same brain sample. Tissue sections were scanned using an inverted microscope system (BZ-9000, KEYENCE, Osaka, Japan), and the fluorescence of the secondary antibodies was separately detected. Cells were analyzed using an image analyzer (BZ-II Analyzer, KEYENCE) with measurement (BZ-H1M, KEYENCE) and cell-counting (BZ-H1C, KEYENCE) software. Designated cell types were recognized by a software algorithm that disregards noise outside of the fluorescence intensity window or signals that are too large or too small to meet the criteria for cell recognition. The conditions of the cell count can be saved across assays, hence leading to high reproducibility between sections. The BrdU-positive cells (red), PV-positive cells (red), GFP-positive cells (green), GAD67-positive cells (green) and co-labeled cells (yellow) were counted in the region of interests. Cell densities were calculated in each region of interest. For analysis of cell distribution in the cerebral cortex, the \% distribution of cells in each brain region was calculated. One to three sections were arbitrarily selected from each animal brain.

\section{Injection of dexamethasone and mifepristone into fetal lateral} ventricles

Dexamethasone (DEX; $1 \mathrm{~mm}$ ) and mifepristone (MIFE; $1 \mathrm{~mm}$, Sigma-Aldrich) were dissolved in $\mathrm{N}$-methyl-2-pyrrolidone (NMP; Wako Pure Chemical Industries, Wako, Japan), and adsorbed on an absorbent polymer nanoparticle poly(lactic-co-glycolic) acid (PLGA, Wako) (1 mg PLGA/4 $\mu$ l NMP). ${ }^{36-38}$ The uterine horns were exposed under anesthesia, and the drug-absorbed PLGA $(0.5 \mu \mathrm{l})$ was bilaterally injected into the lateral ventricles of fetal $\mathrm{GAD}^{+/+}$mice at E15.0 using borosilicate glass capillaries (GC100F-10, Harvard Apparatus, Holliston, MA, USA). Assuming a $0.8 \mathrm{~g}$ water weight for the fetus, the concentration was estimated as 1.25 $\mathrm{nmol} \mathrm{ml} \mathrm{m}^{-1}$, and $20-30 \%$ of the PLGA-adsorbed DEX was expected to be released in 2 days. ${ }^{36}$ The maternal abdomen was then sutured and allowed to recover. Brain sections were prepared as described above for E17.5 fetuses.

\section{TUNEL (TdT-mediated dUTP nick-end labeling) assay}

The TMR red In Situ Cell Death Detection Kit (Roche, Mannheim, Germany) was used in accordance with the manufacturer's protocol. For a positive control, sections were incubated for $15 \mathrm{~min}$ at $37^{\circ} \mathrm{C}$ in proteinase $\mathrm{K}$, followed by treatment with DNase I $\left(10 \mathrm{U} \mathrm{ml}^{-1}\right)$ for $30 \mathrm{~min}$ at $37^{\circ} \mathrm{C}$.

\section{Statistical analysis}

Fetal body weight, maternal serum corticosterone (CORT) levels and the density of immunopositive cells in each area were analyzed using Student's $t$-test. The Pearson $x^{2}$-test was used to evaluate the distribution pattern of migrating cells: tangentially migrating BrdU (injected at E12.0 or 15.0) and GFP double-positive GABAergic cells and radially migrating BrdUpositive and GFP-negative $\mathrm{CP}$ cells born during MS. $P<0.05$ was considered to be significant. 


\section{RESULTS}

Effect of MS on the proliferation and radial migration of CP cells in the GAD67 $7^{+/ G F P}$ fetal brain

Pregnant ${\mathrm{GAD} 67^{+/+}}$mice giving rise to $\mathrm{GAD} 67^{+/ \mathrm{GFP}}$ fetuses were given restraint-and-light stress, and BrdU was used to label cells dividing during this period. BrdU was injected immediately before starting the MS (Figure 1a). After the final session of MS, the brains of GAD67 $7^{+/ G F P}$ fetuses were examined for CP cells and GABAergic neurons generated during MS (Figures $1 \mathrm{~b}$ and $\mathrm{c}$ ).

The density and distribution pattern of CP cells, that is, BrdU $(+)$ /GFP $(-)$ cells, in the CP, subplate (SP), intermediate zone (IZ), IZ/subventricular zone (SVZ) and VZ of the cerebral cortex were investigated. Neither the regional density nor the distribution pattern of CP cells was altered by MS (Figures 1d and e). These results indicate that proliferation and radial migration of $\mathrm{CP}$ cells were unaffected by prenatal stress.

Effect of MS on the population of GABAergic neurons in the GAD67 $7^{+/ G F P}$ fetal cerebral cortex

GABAergic neurons were classified according to GFP expression, and BrdU $(+) / G F P(+)$ cells were counted in the cerebral cortex (Figures $1 \mathrm{~b}$ and $\mathrm{c}$ ) of control and stressed GAD67 $7^{+/ G F P}$ fetuses. BrdU (+) GABAergic neurons were decreased in the IZ, IZ/SVZ and VZ of the stressed fetal cerebral cortex (IZ, control $289 \pm 33$ cells $\mathrm{mm}^{-2}$, stress $78 \pm 30$ cells $\mathrm{mm}^{-2}, F_{1,6}=1.22, P<0.001 ; \mathrm{IZ} / \mathrm{SVZ}$,

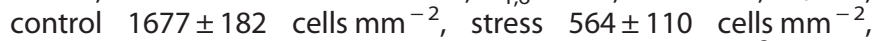
$F_{1,6}=2.74, \quad P<0.001 ; \mathrm{VZ}$, control $469 \pm 67$ cells $\mathrm{mm}^{-2}$, stress $119 \pm 22$ cells $\left.\mathrm{mm}^{-2}, F_{1,6}=9.28, P<0.01\right)$. The density of the BrdU

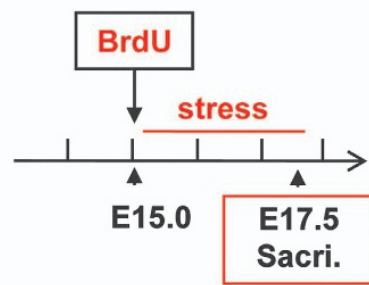

b

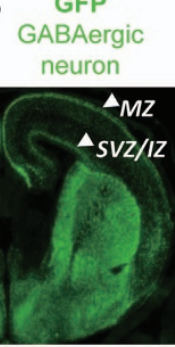

BrdU Birth date marker

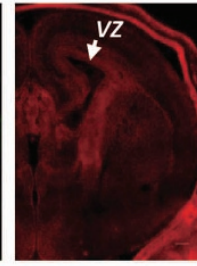

\section{c}
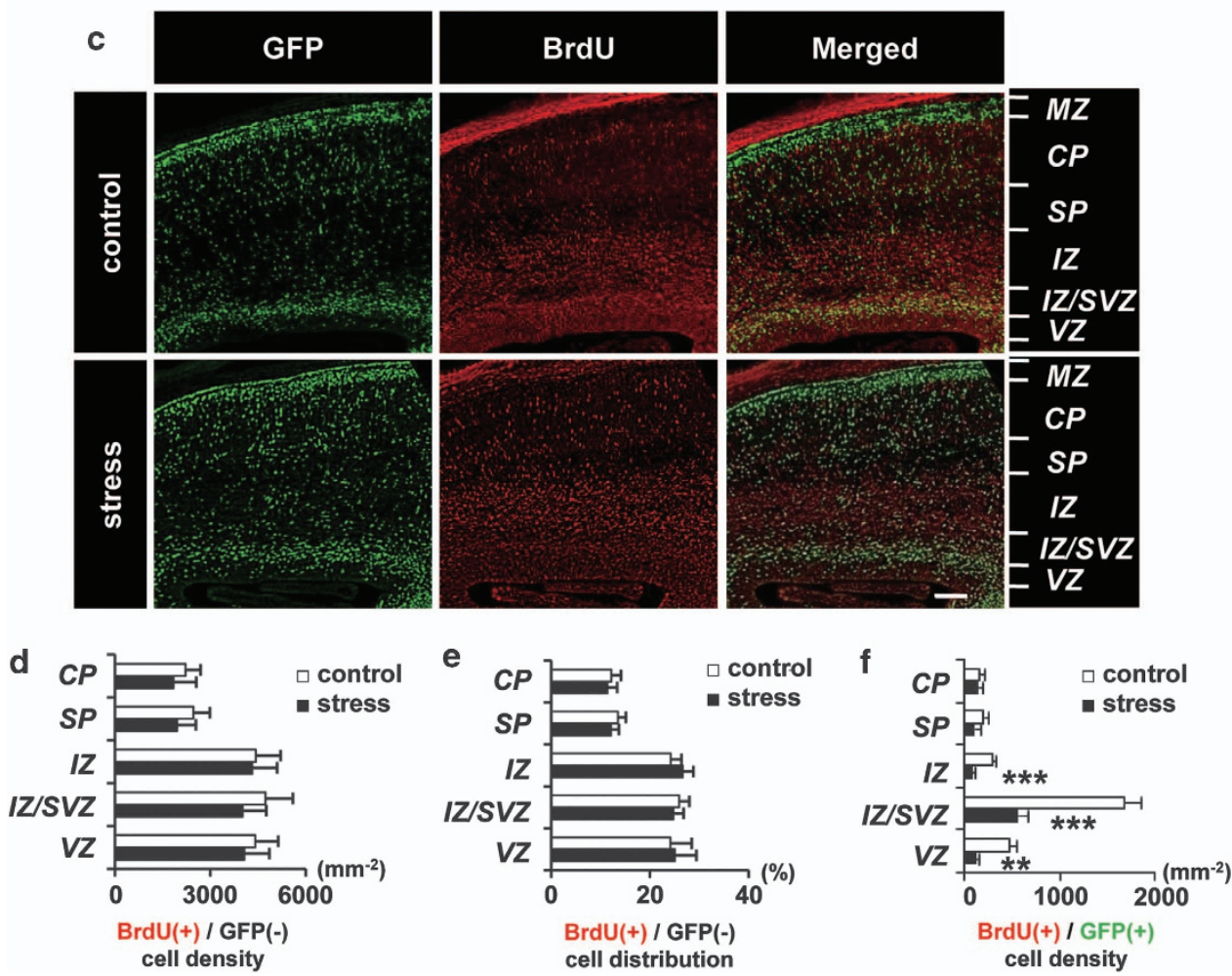

Figure 1. The density of $\gamma$-aminobutyric acidergic (GABAergic) neurons, but not that of cortical plate cells, born during the maternal stress (MS) decreased in the fetal cerebral cortex. (a) Time course of the MS and BrdU administration. BrdU was administered to pregnant mice at E15.0, before the first stress session. GAD67 ${ }^{+/ G F P}$ fetuses were dissected out at E17.5 after the final session of stress. (b) Orientation of the fetal forebrain. Fluorescence images of green fluorescent protein (GFP; green, GABAergic neuron) and BrdU (red, cells born at E15.0) in control and stressed mice. Double-positive cells (yellow) are GABAergic neurons born during the MS. (c) Higher-magnification image of control and the stressed fetal neocortex immunostained with GFP and BrdU antibodies, and their merged image. CP, cortical plate; IZ, intermediate zone; IZ/ SVZ, intermediate zone/subventricular zone; MZ, marginal zone; SP, subplate; VZ, ventricular zone. IZ is divided into IZ/SVZ and the rest of IZ because IZ/SVZ is the main route of tangential migration. ${ }^{31} \mathrm{Bar}=100 \mu \mathrm{m}$. (d) The density of BrdU-positive CP cells, that is, BrdU(+) and GFP( - ), in each neocortical area of maternally stressed fetuses was not affected ( $P>0.05, t$-test in each area). (e) The distribution of BrdU-positive $C P$ cells in each neocortical area was not significantly different between control and stressed mice. $\left(P=0.99\right.$, Pearson's $X^{2}$-test). (f) The density of BrdU-positive GABAergic neurons, that is, BrdU(+) and GFP(+), was significantly decreased in IZ, IZ/SVZ and VZ of the stressed fetal cerebral cortex. ${ }^{* *} P<0.01 ;{ }^{* *} P<0.001, t$-test in each area. Bars represent the mean \pm s.e.m., $n=11$ sections from four pups in each group (d-f). 
a

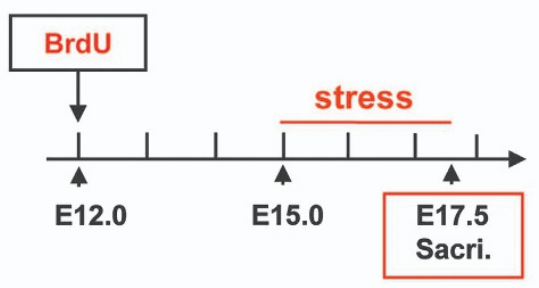

b E17.5 GAD67+/GFP BrdU(E12.0) / GFP

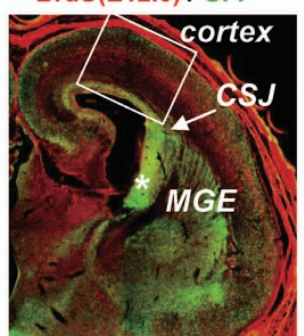

E17.5 GAD67+/GFP

BrdU(E15.0) / GFP

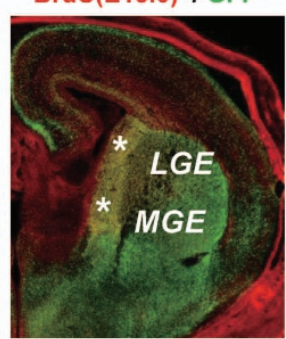

C
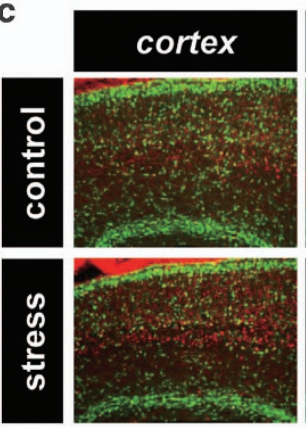

e
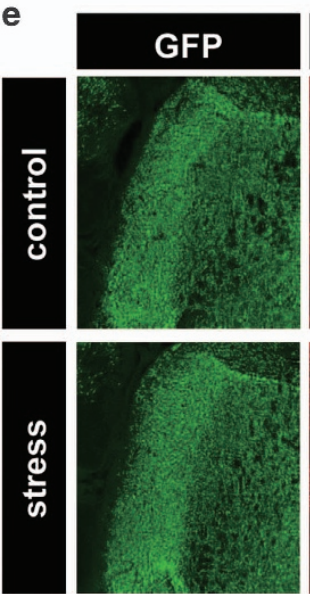
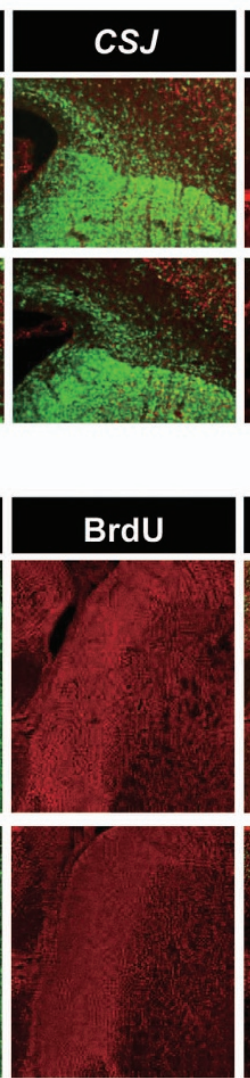

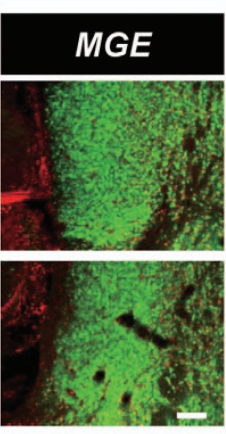

d

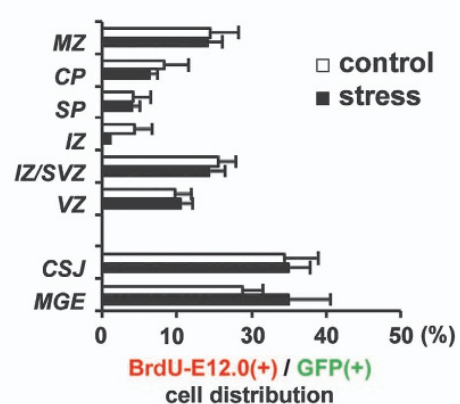

f

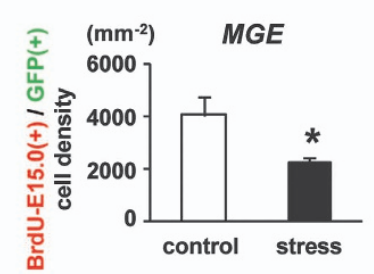

g

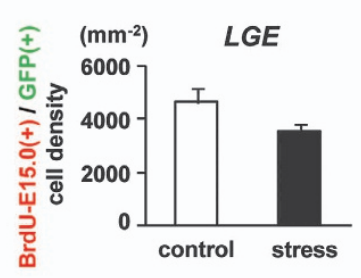

Figure 2. The number of newly born $\gamma$-aminobutyric acidergic (GABAergic) neurons decreased in the medial ganglionic eminence (MGE) following maternal stress (MS). (a) Time course of MS and BrdU injection. BrdU was administered to pregnant mice at E12.0. MS was performed from E15.0 to 17.5, and fetuses were dissected out at E17.5. (b) An E17.5 GAD ${ }^{+/ G P P}$ fetal forebrain injected with BrdU at E12.0 (left) or E15.0 (right). CSJ, corticostriatal junction; LGE, lateral ganglionic eminence. (c) Higher-magnification image of the neocortex showing CSJ and MGE of control and stressed fetal brains in b (left). (d) Distribution of BrdU-positive (injected at E12.0) GABAergic neurons. The \% distribution of BrdU-E12.0(+)/GFP(+) cells in each area of the neocortex and ganglionic eminence (GE) was not significantly different between control and stressed fetuses ( $P=0.85$, Pearson's $\chi^{2}$-test; control: $n=15$ sections from five pups, stress: $n=19$ sections from five pups). Bars represent the mean \pm s.e.m. (e) Higher-magnification image of the section shown in $\mathbf{b}$ (right). MGE and LGE immunostained for green fluorescent protein (GFP) and BrdU (injected at E15.0) and their merged image. Bar =100 $\mu \mathrm{m}$. (f) The density of BrdU-positive GABAergic neurons, BrdU-E15.0 $(+) / G F P(+)$, was significantly decreased by MS in the MGE. ${ }^{*} P<0.05, t$-test; control, $n=11$ sections from seven pups; stress, $n=18$ sections from seven pups). (g) In the LGE, the density of BrdU-positive GABAergic neurons appeared to decrease following MS, but the decrease was not significant ( $P=0.10$, $t$-test; control, $n=11$ sections from seven pups; stress, $n=18$ sections from seven pups). Error bars represent the s.e.m.

and GFP double-positive cells in the control and stressed fetal brains showed no significant differences in the CP and SP (Figure 1f). The total density of BrdU (-)/GFP (+) cells in the fetal cerebral cortex was not altered by MS (data not shown). These data indicate that MS decreases the number of neocortical GABAergic neurons born during the stress period.

Effect of MS on the tangential migration of GABAergic neurons in GAD67 $7^{+/ G F P}$ fetuses

To determine whether prenatal stress retarded tangential migration and resulted in a decrease in GABAergic neurons in the neocortex, we examined the distribution of GABAergic neurons born before the stress period. BrdU was injected at E12.0, and MS was performed from E15.0 to E17.5 (Figure 2a). The distribution pattern of BrdU-GFP double-positive cells in each area of the fetal ganglionic eminence (GE) and the neocortex was unaffected by MS (Figure 2b), indicating that tangential migration was not affected by prenatal stress. 
a

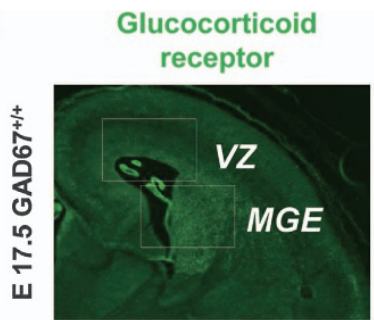

b
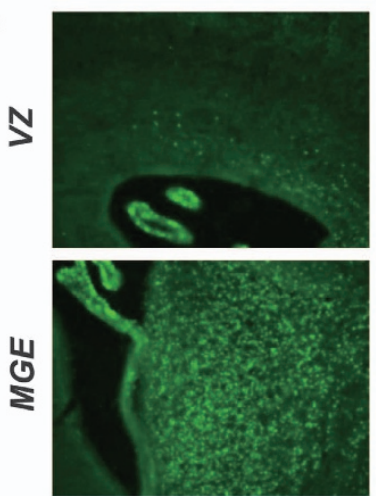

C

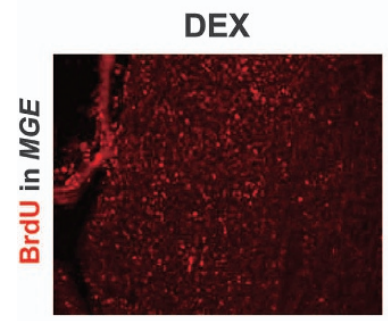

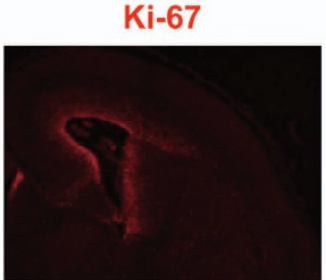
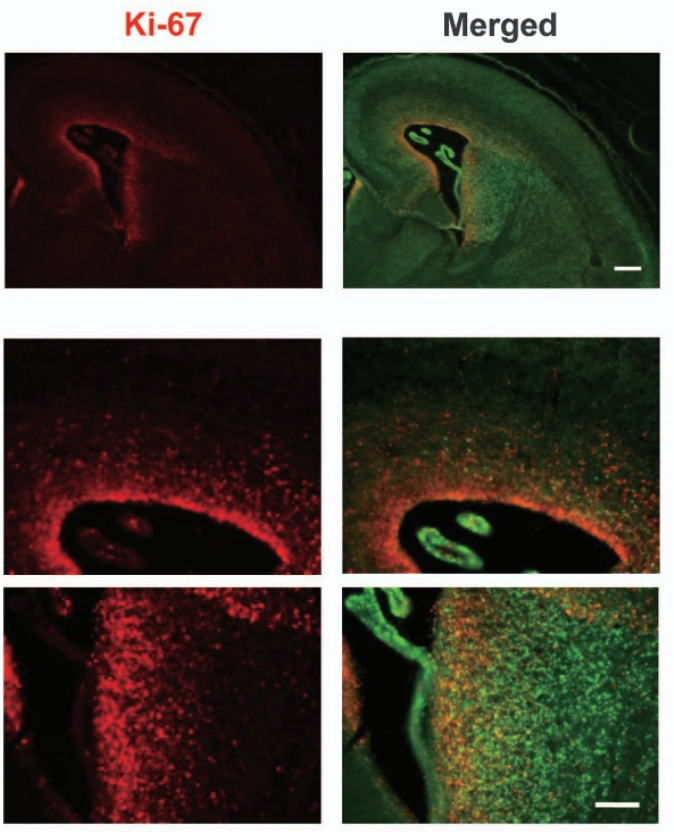

d

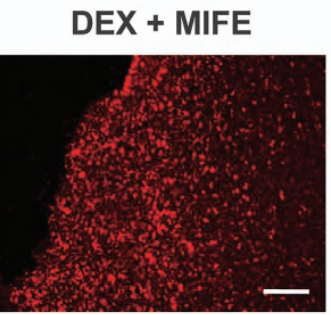

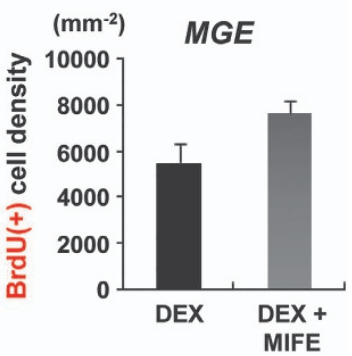

Figure 3. Progenitor $\gamma$-aminobutyric acidergic (GABAergic) interneurons in the medial ganglionic eminence (MGE), but not cortical plate (CP) cells in the ventricular zone (VZ), express glucocorticoid receptor (GR). (a) Immunostaining of GR (green) and Ki-67 (red) and their merged images from E17.5 fetal brain; $n=3$ sections from three pups. (b) Higher-magnification image of (a). Many proliferating cells in the MGE, but not in the VZ, expressed GR. Bars $=50 \mu \mathrm{m}$. (c) BrdU immunostaining at E17.5 in the MGE from either Dexamethasone (DEX) (-) (left) or DEX and mifepristone (MIFE)-treated (right) E15.0 fetuses. (d) The density of BrdU-positive cells in the MGE in DEX and MIFE-treated fetuses was higher than that in DEX-treated fetuses. $P=0.077, t$-test. DEX, $n=3$ sections from three pups; DEX + MIFE, $n=4$ sections from three pups.

Effect of MS on the generation of GABAergic neurons in the ganglionic eminence of GAD67 $7^{+/ G F P}$ fetuses

We investigated the number of BrdU (injected at E15.0) and GFP double-positive cells in the fetal GE (Figure 2e). The number of BrdU-positive GABAergic neurons decreased significantly in the $M G E$, but not in the lateral ganglionic eminence (LGE; Figures $2 f$ and g; MGE, control $4156 \pm 546$ cells $\mathrm{mm}^{-2}$, stress $2373 \pm 270$ cells $\mathrm{mm}^{-2}, F_{1,12}=10.6, P<0.05 ; \mathrm{LGE}$, control $4591 \pm 412$ cells $\mathrm{mm}^{-2}$, stress $3795 \pm 370$ cells $\left.\mathrm{mm}^{-2}, F_{1,12}=5.80, P=0.10\right)$. These data indicate that the number of GABAergic neurons generated in the fetal MGE was significantly decreased during MS.

Distribution pattern of proliferating cells and GRs in fetal brains Because maternally stressed fetuses respond by increasing CORT (Supplementary Figure 1d) ${ }^{29}$, we investigated the localization of GRs in proliferating cells (Figures $3 a$ and $b$ ) to determine why only GABAergic precursors were vulnerable to MS $(n=3)$. Fetal brains were immunostained for GR and Ki-67. Although few GR and Ki-67 double-positive cells were present in the VZ, many double-positive cells were observed in the MGE. These data indicate that the proliferating cells in the MGE, but not in the VZ, can be affected by CORT via GR.
Effect of GR activation on cell proliferation in the MGE

To investigate whether increased CORT (Supplementary Figure 1) is responsible for impairment of neuronal proliferation in the MGE, we administered the GR agonist DEX (1 $\mathrm{mm}$ ) or DEX together with the GR antagonist MIFE (1 $\mathrm{mm}$ ) absorbed on PLGA into the lateral ventricles of $\mathrm{GAD} 67^{+/+}$fetuses at E15 (Figure 3C). Assuming that the bioactivity of DEX at GRs is 20-30 times higher than that of endogenous corticosterone, the total steroid level after DEX injection should be comparable to that in the stressed fetuses. Two days later, the cell density increased by $40 \%$ when the antagonist was co-applied with a GR agonist (Figure 3d; DEX, $5479 \pm 821$ cells mm ${ }^{-2}$, DEX+MIFE, $7618 \pm 570$ cells mm ${ }^{-2}, F_{1,5}$ $=11.56, P=0.077$ ). Although statistical significance was not established, CORT may disturb cell proliferation via GR in the MGE (see Discussion).

Evaluation of cell death in the MGE in GAD67 $7^{+/ G F P}$ fetuses exposed to MS

We used the TUNEL assay to determine whether the decreased number of BrdU (+)/GFP (+) cells was caused by cell death, (Supplementary Figure 2). Several TUNEL-positive cells were observed in the neocortex of both control $(n=3)$ and stressed $(n=4)$ fetal brains (Supplementary Figure 2b), whereas few cells 
a
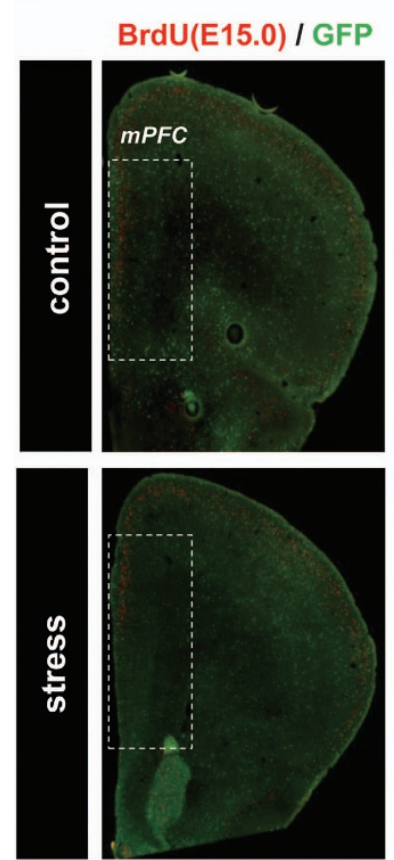

P21 GAD67 $7^{+/ G F P}$
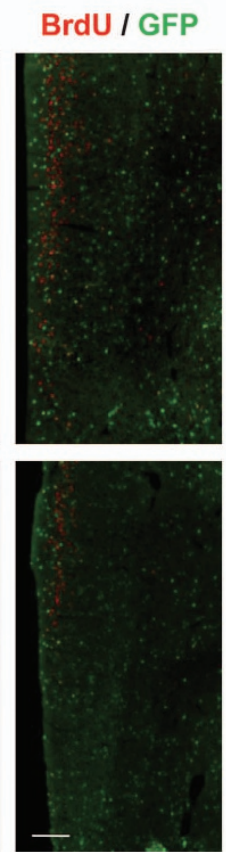

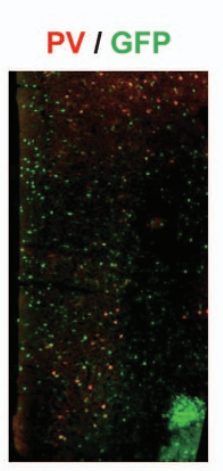

b $\left(\mathrm{mm}^{-2}\right)$
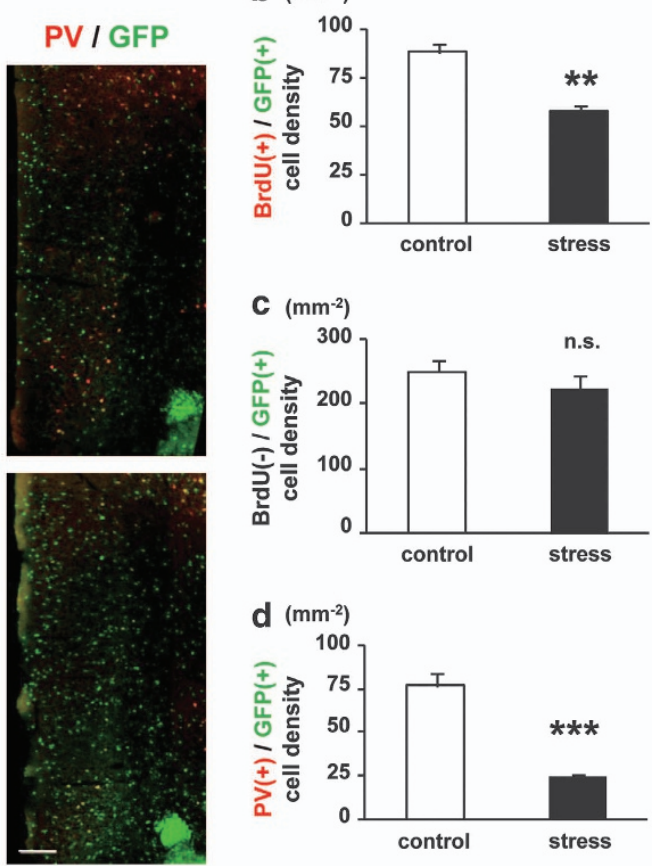

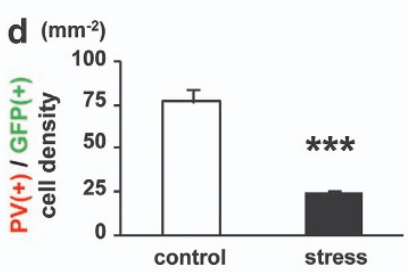

Figure 4. Loss of parvalbumin (PV)-positive $\gamma$-aminobutyric acidergic (GABAergic) interneurons in the medial prefrontal cortex (mPFC) of maternally stressed P21 GAD67 ${ }^{+/ G F P}$ offspring. (a) Region of analysis in the mPFC of a coronal section at P21 (left, dotted square). BrdU was injected at E15.0 immediately before maternal stress (MS). Middle panels are BrdU and green fluorescent protein (GFP) double-positive cells at higher magnification in the region indicated in the left panel (BrdU/GFP). Right panels (PV/GFP) show PV and GFP double-positive cells in the $\mathrm{mPFC}$. Bars $=200 \mu \mathrm{m}$. Note the reduction in double-positive cells in stressed offspring. (b) Quantitative analysis of BrdU and GFP doublepositive cells in the MPFC at P21. The density of BrdU(+)/GFP (+) cells from the stressed group was significantly lower than that of the control ( ${ }^{* *} P<0.01$, $t$-test; control, $n=6$ sections from three brains; stress, $n=7$ sections from four brains). (c) Quantitative analysis of BrdU-negative and GFP-positive cells in the mPFC. There was no significant difference between control and stressed pups $(P=0.68, t$-test; control, $n=6$ sections from three brains; stress, $n=7$ sections from four brains). (d) Quantitative analysis of PV and GFP double-positive cells in the mPFC at P21. The density of PV (+)/GFP (+) cells in the stress group was significantly lower than that of the control $\left(^{* * * P}<0.001, t\right.$-test; control, $n=5$ sections from three brains; stress, $n=5$ sections from four brains). Error bars represent the s.e.m.

were observed in the MGE (Supplementary Figure 2c). However, TUNEL-positive cells were detected in positive control sections treated with DNase I $(n=3)$. Thus, the decrease in GABAergic neurons generated during MS was not caused by cell death.

Anatomical outcome of MS in the brains of P21 GAD67 $7^{+/ G F P}$ offspring

We examined the outcome of the decrease in GABAergic neuronal proliferation in the fetal MGE in P21 male GAD67 $7^{+/ G F P}$ offspring stressed during the fetal period. GABAergic interneurons generated during MS were studied in the medial prefrontal cortex (mPFC), an area involved in impaired cognition in schizophrenia ${ }^{39}$ (Figure 4). The density of BrdU (injected at E15.0) and GFP doublepositive cells was significantly decreased by exposure to MS (Figure 4b; control, $87.97 \pm 4.71$ cells $\mathrm{mm}^{-2}$, stress, $61.95 \pm 3.56$ cells $\mathrm{mm}^{-2}, F_{1,11}=0.20, P<0.01$ ). In contrast, the density of BrdUnegative and GFP-positive cells was not different between the control and stress groups (Figure 4c). These data indicate that impairment of GABAergic neurogenesis during exposure to MS resulted in a reduced number of GABAergic neurons in the MPFC of P21 offspring.

PV-containing interneurons are fundamental to the generation of normal synchronous activity and appear to be impaired in schizophrenia. ${ }^{40}$ The number of PV-positive GABAergic interneurons was also significantly reduced in the mPFC (Figure $4 d$; control, $76.48 \pm 7.16$ cells $\mathrm{mm}^{-2}$, stress, $24.00 \pm 1.82$ cells $\mathrm{mm}^{-2}, F_{1,8}=15.4$, $P<0.001$ ) of $\mathrm{GAD}^{+} 7^{+/ \mathrm{GFP}}$ offspring. Similar reductions were observed in the HIP and the somatosensory cortex (S1), but not in the motor cortex (M1, Supplementary Figures 3a and b). There were no significant differences in PV $(-) / G F P(+)$ cell density in the control and stressed group in any region examined (Supplementary Figures 3a and c).

We next investigated the density of PV and GFP double-positive cells in subregions of the MPFC, HIP and S1 and found significant decreases in all layers of the MPFC (Figures $5 a$ and $c$ ), in the CA1 region of the HIP (Figures $5 \mathrm{~b}$ and e) and in layer III of the S1 (Figures $5 \mathrm{~b}$ and $\mathrm{g}$ ). In contrast, there were no significant differences in PV $(-)$ /GFP $(+)$ cell density in any of the evaluated regions (Figures $5 d, f$ and $h$ ). These data indicate that the number of PV-positive GABAergic interneurons was specifically decreased in specific brain regions of Gad1-heterozygous P21 mice stressed during the fetal period.

Anatomical outcome of MS in the brain of P21 GAD67 $7^{+/+}$offspring Finally, to address the question of whether heterozygous deletion of the Gad1 gene contributes to the loss of PV-positive cells in MSexposed mice, we examined GAD67 $7^{+/+}$offspring (Supplementary Figures $4 \mathrm{a}$ and $\mathrm{b}$ ). No differences were found in the densities of PV and GAD67 double-positive cells between the control and stressed groups in the mPFC (control $83.57 \pm 10.8$ cells $\mathrm{mm}^{-2}$, stress $83.41 \pm 12.8$ cells $\mathrm{mm}^{-2}$ ), HIP (control $63.32 \pm 3.82$ cells $\mathrm{mm}^{-2}$, stress $66.40 \pm 3.46$ cells $\mathrm{mm}^{-2}$ ), M1 (control 207.3 \pm 25.0 cells $\mathrm{mm}^{-2}$, stress $211.0 \pm 17.2$ cells $\mathrm{mm}^{-2}$ ) or $\mathrm{S} 1$ (control $217.9 \pm 12.8$ cells $\mathrm{mm}^{-2}$, stress $184.4 \pm 26.9$ cells $\mathrm{mm}^{-2}$ ) (Supplementary Figure $4 c ; P>0.05, t$-test in each area). These data suggest that MS alone is not sufficient to induce the loss of PV cells. There were also no significant differences in the densities of PV-negative and GAD67-positive cells in these areas 

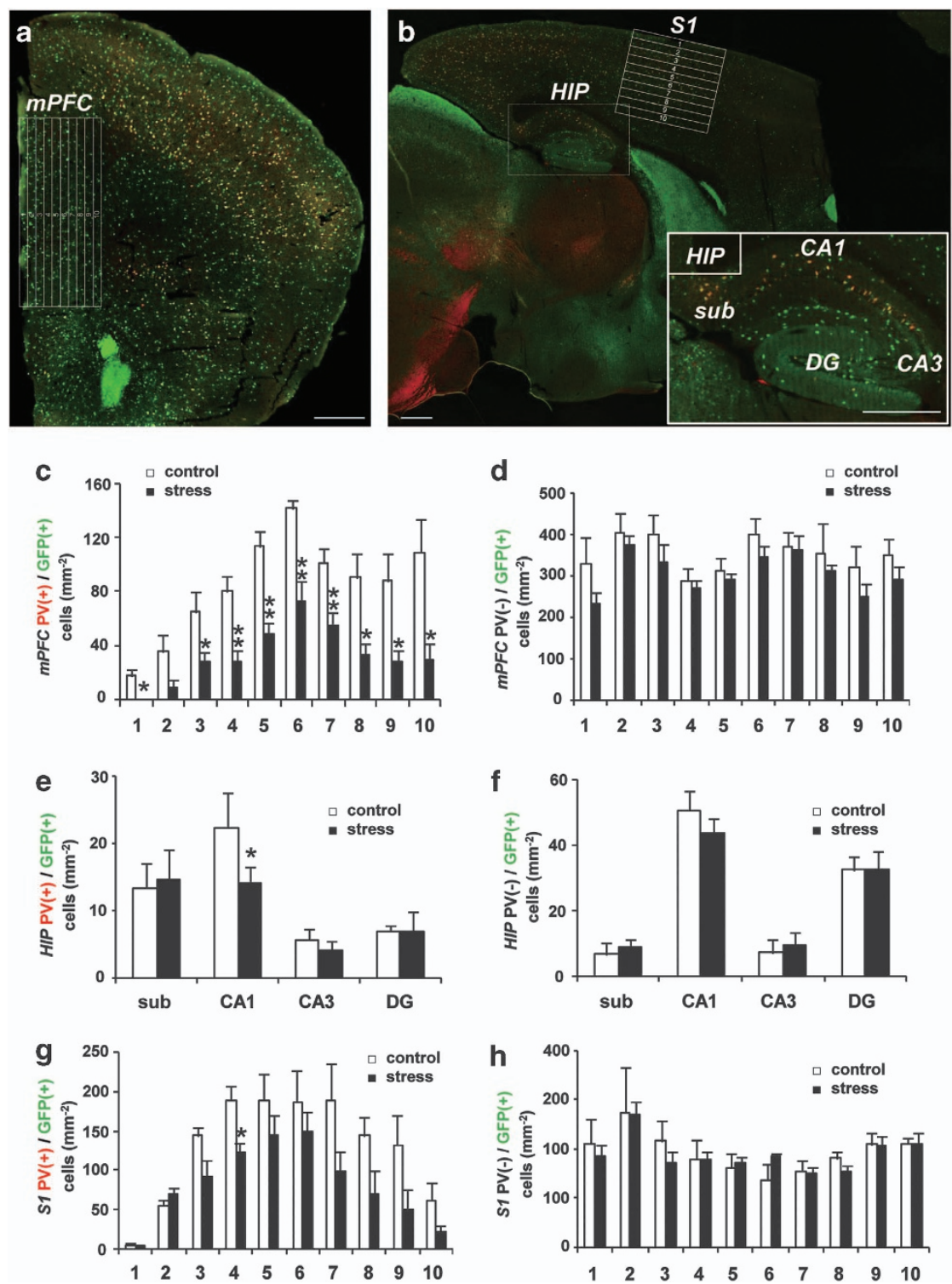

Figure 5. Topography of the reduction of parvalbumin (PV)-positive $\gamma$-aminobutyric acidergic (GABAergic) interneurons following maternal

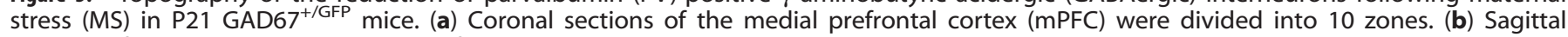
sections of the hippocampus (HIP) were further divided into subregions, and the somatosensory cortex (S1) was divided into 10 zones. Bars in $\mathbf{a}$ and $\mathbf{b}=500 \mu \mathrm{m}$. (c-h) Quantitative analysis of densities of PV $(+) / G F P(+)$ cells $(\mathbf{c}, \mathbf{e}, \mathbf{g})$ and PV $(-) / G F P(+)$ cells $(\mathbf{d}, \mathbf{f}, \mathbf{h})\left({ }^{*} P<0.05,{ }^{* *} P<0.01, t-\right.$ test). (c, d) mPFC: control, $n=5$ sections from three brains; stress, $n=5$ sections from four brains. (e, f) HIP: control, $n=5$ sections from three brains; stress, $n=4$ sections from four brains. (g, h) S1: control, $n=4$ sections from three brains; stress, $n=5$ sections from four brains.

(Supplementary Figure 4d; mPFC, control $194.5 \pm 14.3$ cells $\mathrm{mm}^{-2}$, stress $204.2 \pm 20.5$ cells $\mathrm{mm}^{-2}$; HIP, control $127.2 \pm 27.9$ cells $\mathrm{mm}^{-2}$, stress $120.1 \pm 13.2$ cells $\mathrm{mm}^{-2} ; \mathrm{M} 1$, control $134.4 \pm 16.5$ cells $\mathrm{mm}^{-2}$, stress $115.8 \pm 13.2$ cells $\mathrm{mm}^{-2}$; $\mathrm{S} 1$, control $116.4 \pm 15.3$ cells $\mathrm{mm}^{-2}$, stress $127.4 \pm 13.4$ cells $\mathrm{mm}^{-2} ; P>0.05, t$-test in each area).

\section{DISCUSSION}

MS had a specific impact on the proliferation of PV-positive GABAergic neurons in the GAD67 $7^{+/ G F P}$ fetal brain. The major findings presented here are the following: (1) neurogenesis of GABAergic neurons in the fetal MGE was suppressed during MS, (2) most proliferating cells in the MGE expressed GRs whose activation appeared to affect cell proliferation and (3) the number of PV-positive GABAergic cells in P21 mice stressed during the fetal period was significantly decreased in brain regions considered to be involved in psychiatric illness. ${ }^{41}$ In addition, (4) in contrast to $\mathrm{GAD} 67^{+/ G F P}$ mice, GAD67 ${ }^{+/+}$pups did not show a loss of PV-positive GABAergic cells following MS. Stress during the gestational period ${ }^{2,6}$ and GAD67 abnormalities ${ }^{42,43}$ are both considered to be risk factors for psychiatric disorders that may involve perturbation of neurogenesis. ${ }^{44}$ Thus, our model reproduced both the risks and anatomical outcomes observed in schizophrenia patients, such as a decrease in the number of PVpositive GABAergic interneurons. ${ }^{45,46}$

Under stressful conditions during pregnancy, maternal glucocorticoid concentrations can reach high levels. Although most glucocorticoid is transformed into an inactive form by the placental enzyme $11 \beta$-hydroxysteroid dehydrogenase, ${ }^{47}$ if placental glucocorticoid levels become extremely high, fetal glucocorticoid levels can increase and may affect development. ${ }^{48}$ In our study, maternal serum CORT levels increased twofold following MS, as did fetal CORT levels ${ }^{29}$ (Supplementary Figures $1 \mathrm{c}$ and d). Thus, the CORT discharged from the maternal adrenal cortex 
during stress may have been transferred to the fetus through the placenta, thereby perturbing brain development through GRs.

CORT influences the proliferation of embryonic neuronal stem cells by activating GRs. ${ }^{49}$ Our results show that proliferating cells in the MGE have GRs, but few such cells were observed in the VZ (Figure 3b). Thus, CORT increases by MS could exclusively inhibit the proliferation of GABAergic progenitors expressing GRs. Furthermore, in our previous study, fetal CORT levels in GAD67 $7^{+\prime}$ GFP mice were significantly higher than those in $\mathrm{GAD} 67^{+/+}$mice with or without MS. ${ }^{29}$ Therefore, heterozygosity of the Gad1 gene encoding GAD67 may influence CORT levels during MS. In addition, GAD67 and ambient GABA may provide an essential environment for neurogenesis of GABAergic neurons, ${ }^{50-53}$ because exogenous DEX administration had a rather subtle impact on $\mathrm{GAD}^{+/+}$fetuses (Figure 3b). Decreased GAD67 expression is increasingly recognized in the postmortem brains of schizophrenia patients and other major psychiatric diseases ${ }^{22,24,42,54-56}$ including autism. ${ }^{57}$ Thus, GAD1 abnormalities may be a genetic risk factor that could interact with environmental risk factors such as MS to generate psychiatric disorders. ${ }^{58,59}$

In contrast to our results, administration of an exogenous stress hormone retarded the radial migration of CP cells. ${ }^{60}$ As demonstrated in Figures 1 and 2, neither radial migration nor tangential migration was altered by exposure to MS. Intrinsic stress hormones may have less of an effect on GRs compared with exogenous synthetic compounds. In addition, in our results, lower expression of GRs was observed in proliferating cells from the VZ and in other neocortical regions when compared with the MGE (Figure 3). Thus, retardation of radial migration may require higher concentrations of glucocorticoids. ${ }^{60}$ In addition, a recent study reported impaired tangential migration following MS at the earliest time point (E12). ${ }^{61}$ Thus, the influence of MS may depend on the period of exposure, for example, MS at later gestational stages, such as in our model, does not affect tangential migration but affects the generation of GABAergic neurons.

Decreased PV mRNA levels appear to be common in schizophrenia patients. ${ }^{62,63}$ The present study demonstrates for the first time a decrease in GABAergic neurogenesis in fetuses and loss of PV-positive interneurons in P21 mice exposed to MS during the fetal period. In schizophrenia patients, decreased neuronal PV mRNA expression is highly associated with a decrease in the density of neurons expressing GAD67 mRNA, and only half of PV mRNA-positive neurons were found to have detectable levels of GAD67 mRNA. ${ }^{64}$ In the present study, the population of GABAergic interneurons generated during MS decreased. Of these cells, the number of PV-positive GABAergic interneurons was significantly decreased in the mPFC, HIP and S1 of GAD67 $7^{+/ G F P}$ mice but not $\mathrm{GAD} 7^{+/+}$mice. Furthermore, PV-negative GABAergic interneurons were not affected in both genotypes. These results indicate that exposure to MS, in addition to heterozygous deletion of Gad1, exclusively has an impact on the proliferation of GABAergic neuronal precursors fated to be PV-positive.

Some genetic model animals of schizophrenia show decreases in PV-positive neurons in the mPFC. ${ }^{65}$ Interneuron subgroups have distinct spatial and temporal origins, with cortical PV-expressing interneurons originating primarily within the $\mathrm{MGE}^{66}$ and notably at approximately E15. ${ }^{67}$ In our model, proliferation during E15.0 to E17.5 in the MGE was significantly decreased (Figure 2) by MS applied during that period, suggesting that the generation of PVexpressing neurons destined to migrate into the MPFC, the CA1 of the HIP and layer III of the S1 was disturbed. Cortical and hippocampal PV-positive interneurons have a crucial role in cognitive function and working memory. ${ }^{68-70}$ Therefore, impairment of these cells could underlie working memory impairment in schizophrenia patients. ${ }^{71,72}$

MS applied to the mothers of GAD67-heterozygous fetuses caused damage to the embryonic brains, especially to precursor cells destined to be PV-positive GABAergic interneurons in particular cortical regions, which recapitulates the morphological abnormality observed in psychiatric disorders. Considering that GAD67 homozygous offspring did not show such outcomes following MS, this finding could explain the selective loss of PVpositive GABAergic interneurons observed in specific brain regions in patients with GAD67 abnormalities exposed to MS. Thus, by providing evidence for an interactive effect of GAD1 and MS on the abnormal phenotype of PV neurons, the present results provide mechanistic insight into the interactions between genetic and environmental risk factors in the etiology of schizophrenia and other psychiatric disorders.

\section{CONFLICT OF INTEREST}

The authors declare no conflict of interest.

\section{ACKNOWLEDGMENTS}

We thank Dr Y Oki, Dr T Kumada, Mr T Morishima, Mr H Saito and Mr T Tashiro for assistance with the experiments. We also thank Dr D. Nakahara for encouragement and discussion on stress model experiments. This work was supported by Grants-inAid for Scientific Research on Priority Areas (\#21026013) and Innovative Area (\#23115506), from the Ministry of Education, Culture, Sports, Science and Technology, Japan (to AF) and Grants-in-Aid for Scientific Research (B) \#22390041, \#25293052 and for Challenging Exploratory Research \#23659535, \#24659508 from the Japan Society for the Promotion of Science (to AF) and Takeda Science Foundation (to YY).

\section{REFERENCES}

1 King S, Laplante D, Joober R. Understanding putative risk factors for schizophrenia: retrospective and prospective studies. J Psychiatry Neurosci 2005; 30: 342-348.

2 Harris A, Seckl J. Glucocorticoids, prenatal stress and the programming of disease. Horm Behav 2011; 59: 279-289.

3 Markham JA, Koenig Jl. Prenatal stress: role in psychotic and depressive diseases. Psychopharmacology 2011; 214: 89-106.

4 Khashan AS, Abel KM, McNamee R, Pedersen MG, Webb RT, Baker PN et al. Higher risk of offspring schizophrenia following antenatal maternal exposure to severe adverse life events. Arch Gen Psychiatry 2008; 65: 146-152.

5 Kapoor A, Matthews SG. Short periods of prenatal stress affect growth, behaviour and hypothalamo-pituitary-adrenal axis activity in male guinea pig offspring. $J$ Physiol 2005; 566: 967-977.

6 Weinstock M. The long-term behavioural consequences of prenatal stress. Neurosci Biobehav Rev 2008; 32: 1073-1086.

7 Fenoglio KA, Brunson KL, Baram TZ. Hippocampal neuroplasticity induced by early-life stress: functional and molecular aspects. Front Neuroendocrinol 2006; 27 180-192.

8 Fumagalli F, Molteni R, Racagni G, Riva MA. Stress during development: Impact on neuroplasticity and relevance to psychopathology. Prog Neurobiol 2007; 81: 197-217.

9 Van den Hove DL, Steinbusch HW, Scheepens A, Van de Berg WD, Kooiman LA Boosten BJ et al. Prenatal stress and neonatal rat brain development. Neuroscience 2006; 137: 145-155.

10 Stolp H, Neuhaus A, Sundramoorthi R, Molnár Z. The long and the short of it: gene and environment interactions during early cortical development and consequences for long-term neurological disease. Front Psychiatry 2012; 3: 50.

11 Nadarajah B, Parnavelas JG. Modes of neuronal migration in the developing cerebral cortex. Nat Rev Neurosci 2002; 3: 423-432.

12 Marin O, Rubenstein JL. Cell migration in the forebrain. Annu Rev Neurosci 2003; 26: 441-483.

13 Anderson SA, Eisenstat DD, Shi L, Rubenstein JL. Interneuron migration from basal forebrain to neocortex: dependence on Dlx genes. Science 1997; 278: 474-476.

14 Tamamaki N, Fujimori KE, Takauji R. Origin and route of tangentially migrating neurons in the developing neocortical intermediate zone. J Neurosci 1997; 17: 8313-8323.

15 Nakajima K. Control of tangential/non-radial migration of neurons in the developing cerebral cortex. Neurochem Int 2007; 51: 121-131.

16 Gonzalez-Burgos G, Fish KN, Lewis DA. GABA neuron alterations, cortical circuit dysfunction and cognitive deficits in schizophrenia. Neural Plast 2011; 2011: 723184.

17 Rossignol E. Genetics and function of neocortical GABAergic interneurons in neurodevelopmental disorders. Neural Plast 2011; 2011: 649325. 
18 Perry TL, Kish SJ, Buchanan J, Hansen S. Gamma-aminobutyric-acid deficiency in brain of schizophrenic patients. Lancet 1979; 1: 237-239.

19 Nakazawa K, Zsiros V, Jiang Z, Nakao K, Kolata S, Zhang S et al. GABAergic interneuron origin of schizophrenia pathophysiology. Neuropharmacology 2012; 62: 1574-1583.

20 Simpson MDC, Slater P, Deakin JFW, Royston MC, Skan WJ. Reduced GABA uptake sites in the temporal lobe in schizophrenia. Neurosci Lett 1989; 107: 211-215.

21 Akbarian S, Kim JJ, Potkin SG, Hagman JO, Tafazzoli A, Bunney WEJr et al. Gene expression for glutamic acid decarboxylase is reduced without loss of neurons in prefrontal cortex of schizophrenics. Arch Gen Psychiatry 1995; 52: 258-266.

22 Guidotti A, Auta J, Davis JM, Di-Giorgi-Gerevini V, Dwivedi Y, Grayson DR et al. Decrease in reelin and glutamic acid decarboxylase67 (GAD67) expression in schizophrenia and bipolar disorder: a postmortem brain study. Arch Gen Psychiatry 2000; 57: 1061-1069.

23 Woo TU, Walsh JP, Benes FM. Density of glutamic acid decarboxylase 67 messenger RNA-containing neurons that express the $\mathrm{N}$-methyl-D-aspartate receptor subunit NR2A in the anterior cingulate cortex in schizophrenia and bipolar disorder. Arch Gen Psychiatry 2004; 61: 649-657.

24 Addington AM, Gornick M, Duckworth J, Sporn A, Gogtay N, Bobb A et al. GAD1 (2q31.1), which encodes glutamic acid decarboxylase (GAD67), is associated with childhood-onset schizophrenia and cortical gray matter volume loss. Mol Psychiatry 2005; 10: 581-588.

25 Wonders CP, Anderson SA. The origin and specification of cortical interneurons. Nat Rev Neurosci 2006; 7: 687-696.

26 Zhang ZJ, Reynolds GP. A selective decrease in the relative density of parvalbumin-immunoreactive neurons in the hippocampus in schizophrenia. Schizophr Res 2002; 55: 1-10.

27 Lewis DA, Gonzalez-Burgos G. Neuroplasticity of neocortical circuits in schizophrenia. Neuropsychopharmacology 2008; 33: 141-165.

28 Beasley $\mathrm{CL}$, Reynolds GP. Parvalbumin-immunoreactive neurons are reduced in the prefrontal cortex of schizophrenics. Schizophr Res 1997; 24: 349-355.

29 Uchida T, Oki Y, Yanagawa Y, Fukuda A. A heterozygous deletion in the glutamate decarboxylase 67 gene enhances maternal and fetal stress vulnerability. Neurosci Res 2011; 69: 276-282.

30 Tamamaki N, Yanagawa Y, Tomioka R, Miyazaki J, Obata K, Kaneko T. Green fluorescent protein expression and colocalization with calretinin, parvalbumin, and somatostatin in the GAD67-GFP knock-in mouse. J Comp Neurol 2003; 467: 60-79.

31 Tanaka D, Nakaya Y, Yanagawa Y, Obata K, Murakami F. Multimodal tangential migration of neocortical GABAergic neurons independent of GPI-anchored proteins. Development 2003; 130: 5803-5813.

32 Wang Y, Kakizaki T, Sakagami H, Saito K, Ebihara S, Kato M et al. Fluorescent labeling of both GABAergic and glycinergic neurons in vesicular GABA transporter (VGAT)-Venus transgenic mouse. Neuroscience 2009; 164: 1031-1043.

33 Morishima T, Uematsu M, Furukawa T, Yanagawa Y, Fukuda A, Yoshida S. GABA imaging in brain slices using immobilized enzyme-linked photo analysis. Neurosci. Res. 2010; 67: 347-353.

34 Coggeshall RE, Lekan HA. Methods for determining numbers of cells and synapses: a case for more uniform standards of review. J Comp Neurol 1996; 364: 6-15.

35 Guillery RW. On counting and counting errors. J Comp Neurol 2002; 447: 1-7.

$36 \mathrm{Kim} \mathrm{D-H}$, Martin DC. Sustained release of dexamethasone from hydrophilic matrices using PLGA nanoparticles for neural drug delivery. Biomaterials 2006; 27: 3031-3037.

37 Kranz H, Brazeau GA, Napaporn J, Martin RL, Millard W, Bodmeier R. Myotoxicity studies of injectable biodegradable in-situ forming drug delivery systems. Int J Pharm 2001; 212: 11-18.

38 Wischke C, Zhang Y, Mittal S, Schwendeman SP. Development of PLGA-based injectable delivery systems for hydrophobic fenretinide. Pharm Res 2010; 27: 2063-2074.

39 Lewis DA, Hashimoto T, Volk DW. Cortical inhibitory neurons and schizophrenia. Nat Rev Neurosci 2005; 6: 312-324

40 Woo TU, Spencer K, McCarley RW. Gamma oscillation deficits and the onset and early progression of schizophrenia. Harv Rev Psychiatry 2010; 18: 173-189.

41 Meyer-Lindenberg AS, Olsen RK, Kohn PD, Brown T, Egan MF, Weinberger DR et al. Regionally specific disturbance of dorsolateral prefrontal-hippocampal functional connectivity in schizophrenia. Arch Gen Psychiatry 2005; 62: 379-386.

42 Volk DW, Lewis DA. Impaired prefrontal inhibition in schizophrenia: relevance for cognitive dysfunction. Physiol Behav 2002; 77: 501-505.

43 Hyde TM, Lipska BK, Ali T, Mathew SV, Law AJ, Metitiri OE et al. Expression of GABA signaling molecules KCC2, NKCC1, and GAD1 in cortical development and schizophrenia. J Neurosci 2011; 31: 11088-11095.

44 Kim JY, Liu CY, Zhang F, Duan X, Wen Z, Song J et al. Interplay between DISC1 and GABA signaling regulates neurogenesis in mice and risk for schizophrenia. Cell 2012; 148: 1051-1064.
45 Volman V, Behrens MM, Sejnowski TJ. Downregulation of parvalbumin at cortical GABA synapses reduces network gamma oscillatory activity. J Neurosci 2011; 31: 18137-18148.

46 Ibi D, Nagai T, Koike H, Kitahara Y, Mizoguchi H, Niwa $\mathrm{M}$ et al. Combined effect of neonatal immune activation and mutant DISC1 on phenotypic changes in adulthood. Behav Brain Res 2010; 206: 32-37.

47 Seckl JR, Holmes MC. Mechanisms of disease: glucocorticoids, their placental metabolism and fetal 'programming' of adult pathophysiology. Nat Clin Pract Endocrinol Metab 2007; 3: 479-488.

48 Charil A, Laplante DP, Vaillancourt C, King S. Prenatal stress and brain development. Brain Res Rev 2010; 65: 56-79.

49 Sundberg M, Savola S, Hienola A, Korhonen L, Lindholm D. Glucocorticoid hormones decrease proliferation of embryonic neural stem cells through ubiquitinmediated degradation of cyclin D1. J Neurosci 2006; 26: 5402-5410.

50 LoTurco JJ, Owens DF, Heath MJ, Davis MB, Kriegstein AR. GABA and glutamate depolarize cortical progenitor cells and inhibit DNA synthesis. Neuron 1995; 15: 1287-1298.

51 Haydar TF, Wang F, Schwartz ML, Rakic P. Differential modulation of proliferation in the neocortical ventricular and subventricular zones. J Neurosci 2000; 20: 5764-5774.

52 Andäng M, Hjerling-Leffler J, Moliner A, Lundgren TK, Castelo-Branco G, Nanou E et al. Histone $\mathrm{H} 2 \mathrm{AX}$-dependent $\mathrm{GABA}_{\mathrm{A}}$ receptor regulation of stem cell proliferation. Nature 2008; 451: 460-464.

53 Egawa K, Fukuda A. Pathophysiological power of improper tonic GABA $A_{A}$ conductances in mature and immature models. Front Neural Circuits 2013; 7: 170.

54 Volk DW, Austin MC, Pierri JN, Sampson AR, Lewis DA. Decreased glutamic acid decarboxylase67 messenger RNA expression in a subset of prefrontal cortical gamma-aminobutyric acid neurons in subjects with schizophrenia. Arch Gen Psychiatry 2000; 57: 237-245.

55 Heckers S, Stone D, Walsh J, Shick J, Koul P, Benes FM. Differential hippocampal expression of glutamic acid decarboxylase 65 and 67 messenger RNA in bipolar disorder and schizophrenia. Arch Gen Psychiatry 2002; 59: 521-529.

56 Fatemi SH, Stary JM, Earle JA, Araghi-Niknam M, Eagan E. GABAergic dysfunction in schizophrenia and mood disorders as reflected by decreased levels of glutamic acid decarboxylase 65 and $67 \mathrm{kDa}$ and Reelin proteins in cerebellum. Schizophr Res 2005; 72: 109-122.

57 Fatemi SH, Halt AR, Stary JM, Kanodia R, Schulz SC, Realmuto GR. Glutamic acid decarboxylase 65 and $67 \mathrm{kDa}$ proteins are reduced in autistic parietal and cerebellar cortices. Biol Psychiatry 2002; 52: 805-810.

58 Straub RE, Lipska BK, Egan MF, Goldberg TE, Callicott JH, Mayhew MB et al. Allelic variation in GAD1 (GAD67) is associated with schizophrenia and influences cortical function and gene expression. Mol Psychiatry 2007; 12: 854-869.

59 Lisman JE, Coyle JT, Green RW, Javitt DC, Benes FM, Heckers S et al. Circuit-based framework for understanding neurotransmitter and risk gene interactions in schizophrenia. Trends Neurosci 2008; 31: 234-242.

60 Fukumoto K, Morita T, Mayanagi T, Tanokashira D, Yoshida T, Sakai A et al. Detrimental effects of glucocorticoids on neuronal migration during brain development. Mol Psychiatry 2009; 14: 1119-1131.

61 Stevens HE, Su T, Yanagawa Y, Vaccarino FM. Prenatal stress delays inhibitory neuron progenitor migration in the developing neocortex. Psycho neuroendocrinology 2013; 38: 509-521.

62 Hashimoto T, Bazmi HH, Mirnics K, Wu Q, Sampson AR, Lewis DA. Conserved regional patterns of GABA-related transcript expression in the neocortex of subjects with schizophrenia. Am J Psychiatry 2008; 165: 479-489.

63 Fung SJ, Webster MJ, Sivagnanasundaram S, Duncan C, Elashoff M, Weickert CS. Expression of interneuron markers in the dorsolateral prefrontal cortex of the developing human and in schizophrenia. Am J Psychiatry 2010; 167: 1479-1488.

64 Hashimoto T, Volk DW, Eggan SM, Mirnics K, Pierri JN, Sun Z et al. Gene expression deficits in a subclass of GABA neurons in the prefrontal cortex of subjects with schizophrenia. J Neurosci 2003; 23: 6315-6326.

65 Carlson GC, Talbot K, Halene TB, Gandal MJ, Kazi HA, Schlosser L et al. Dysbindin-1 mutant mice implicate reduced fast-phasic inhibition as a final common disease mechanism in schizophrenia. Proc Natl Acad Sci USA 2011; 108: E962-E970.

$66 \mathrm{Xu} \mathrm{Q}$, Cobos I, De La Cruz E, Rubenstein JL, Anderson SA. Origins of cortical interneuron subtypes. J Neurosci 2004; 24: 2612-2622.

67 Inan M, Welagen J, Anderson SA. Spatial and temporal bias in the mitotic origins of somatostatin- and parvalbumin-expressing interneuron subgroups and the chandelier subtype in the medial ganglionic eminence. Cereb Cortex 2012; 22: 820-827.

68 Hartwich K, Pollak T, Klausberger T. Distinct firing patterns of identified basket and dendrite-targeting interneurons in the prefrontal cortex during hippocampal theta and local spindle oscillations. J Neurosci 2009; 29: 9563-9574.

69 Silver H, Feldman P, Bilker W, Gur RC. Working memory deficit as a core neuropsychological dysfunction in schizophrenia. Am J Psychiatry 2003; 160: 1809-1816. 
70 Henseler I, Falkai P, Gruber O. A systematic fMRI investigation of the brain systems subserving different working memory components in schizophrenia. Eur J Neurosci 2009; 30: 693-702.

71 Timofeeva OA, Levin ED. Glutamate and nicotinic receptor interactions in working memory: importance for the cognitive impairment of schizophrenia. Neuroscience 2011; 195: 21-36.

Supplementary Information accompanies the paper on the Translational Psychiatry website (http://www.nature.com/tp)
72 Lewis DA, Curley AA, Glausier JR, Volk DW. Cortical parvalbumin interneurons and cognitive dysfunction in schizophrenia. Trends Neurosci 2012; 35: 57-67.

(c) (1) (2) This work is licensed under a Creative Commons AttributionNo ${ }_{\text {BA }}$ NA Commercial-ShareAlike 3.0 Unported License. To view a copy of this license, visit http://creativecommons.org/licenses/by-nc-sa/3.0/ 